\title{
Wall formation by Candida albicans yeast cells: synthesis, secretion and incorporation of two types of mannoproteins
}

\author{
Antonio Marcilla, ${ }^{1}$ Salvador Mormeneo, ${ }^{1}$ M. Victoria Elorza, ${ }^{1}$ J. Jose Manclus ${ }^{2}$ \\ and RafaEl SENTANDREU ${ }^{1 *}$ \\ ${ }^{1}$ Departamento de Microbiologia, Facultat de Farmacia, Universitat de València, Avgda. Blasco Ibañez 13, \\ València 46010, Spain \\ ${ }^{2}$ Laboratorio Integrado de Bioingeniería. Universidad Politécnica de València, Camino de Vera, s/n. València, Spain
}

(Received 1 February 1993; revised 3 August 1993; accepted 5 August 1993)

\begin{abstract}
The mannoprotein components solubilized from the walls of Candida albicans blastoconidia following degradation of the glucan network with $\beta$-glucanase (Zymolyase) have higher molecular masses than their probable precursors present in the supernatant of regenerating protoplasts. It therefore appears that the mannoproteins are released from the walls as part of supramolecular complexes. Immunological analysis using both polyclonal and monoclonal antibodies has demonstrated the probable relationship between molecules found in a mixed membrane preparation, those secreted by regenerating protoplasts, and those present in yeast cell walls. Some mannoproteins secreted by protoplasts incubated in the presence of tunicamycin had significantly increased mobility on SDS-PAGE, whereas others were not affected by the treatment. It is therefore possible that two types of mannoproteins are secreted by protoplasts: one carrying $N$-glycosylated chains (mannan) and one lacking them. All the proteins secreted in the presence of tunicamycin stained with Concanavalin A-peroxidase, demonstrating that they all, including the $N$ glycosylated ones, carried $\boldsymbol{O}$-glycosylated sugar residues. Both classes of mannoproteins, secreted independently of each other, were found in the molecular complexes rendered soluble from the wall by Zymolyase digestion. Data obtained with a monoclonal antibody demonstrated the presence of a repeated epitope within one wall protein(s) detectable in a mixed membrane preparation and in the wall complexes released by Zymolyase.
\end{abstract}

\section{Introduction}

Candida albicans is a dimorphic fungus that exhibits a yeast morphology (blastoconidia) when it grows as an endogenous commensal in the gut of mammals but forms septate hyphae and/or pseudohyphae, as well as blastoconidia, during the initial interaction with human cells and subsequent colonization of tissues (for recent reviews see Calderone \& Braun, 1991; Odds, 1979). Formation of filamentous cells seems to play an essential role in the production of candidal lesions and helps in adhesion to the host epithelium (Kimura \& Pearsall, 1978; Lee \& King, 1983; Sobel et al., 1984). In addition, C. albicans also shows different switching systems that affect wall morphology, antigenicity, drug sensitivity and other

\footnotetext{
*Author for correspondence. Tel +3463864299 ; fax +346386 4682.

Abbreviations: mAb, monoclonal antibody; HMM, high-molecularmass.
}

aspects of its biology (for a review see Soll et al., 1991). Special reference to the white-opaque switching system is important because of the dramatic differences in size, shape and antigenicity of the cells involved (Anderson et al., 1989, 1990). Variation in surface immunological determinants between isolates, between stages of growth and between individual cells has been detected with the help of monoclonal antibodies (Sundstrom et al., 1988), suggesting that the cell walls of $C$. albicans are dynamic structures which respond to environmental changes (Brawner \& Cutler, 1986; Li \& Cutler, 1991; Torosantucci et al., 1990).

To understand how these changes occur, a deeper understanding of cell-wall structure and biosynthesis is needed. The cell walls of $C$. albicans are composed mainly of glucan, chitin and mannoproteins, although how they are synthesized and interconnected is largely unknown (Shepherd et al., 1985). Synthesis of cell wall components may proceed in two steps: first, synthesis and secretion of mannoproteins and vectorial extrusion of chitin and glucan, and second, interaction and 
assembly of the polymers outside the plasma membrane to form the cell walls (Wessels et al., 1990). Very little is known about the biosynthesis and secretion of cell wall mannoproteins in C. albicans. In Saccharomyces cerevisiae, extracellular mannoproteins such as invertase are synthesized on rough endoplasmic reticulum and, following their final glycosylation, are transported via vesicles derived from the Golgi apparatus and secreted by exocytosis (Schekman \& Novick, 1982). The precise route involved in the synthesis of cell wall mannoproteins is not known. However, once in the periplasmic space a significant degree of molecular processing may occur (Sentandreu et al., 1991). The molecular mechanisms involved in this processing are largely unknown but should lead to the formation of several types of bonds (covalent, ionic, etc.) between macromolecules which render them insoluble. This would result in the diverse three-dimensional structures responsible for the different morphologies. Glucan and chitin in Schizophyllum commune are connected by covalent bridges (Sonnenberg et al., 1982; Wessels et al., 1983), and linkages between mannoproteins and glucose molecules (glucans) have been suggested in Sacch. cerevisiae (van Rinsum et al., 1991). However, the nature of the linkages is still a matter of speculation. In $C$. albicans the existence of glycosidic bonds between chitin and 1,6- $\beta$-glucan has been reported (Surarit et al., 1988), and covalent bridges between glucans and mannoproteins (Elorza et al., 1985) and chitin and mannoproteins (Marcilla et al., 1991) have been suggested. Unfortunately, there are few studies of this type although such information may be of help in understanding the dynamic properties of the C. albicans cell wall and its relationship to dimorphism, virulence and phenotypic variation.

In this paper we present information on mannoproteins and demonstrate a possible precursor-product relationship between proteins found in a mixed membrane preparation, in the supernatant of regenerating protoplasts and in the wall of $C$. albicans yeast cells.

\section{Methods}

Strain. The organism used was $C$. albicans ATCC 26555; it was maintained by subculturing every 2-3 weeks on Sabouraud-dextrose agar and propagated in Lee medium (Lee et al., 1975). Erlenmeyer flasks $(500 \mathrm{ml}$ ) containing $150 \mathrm{ml}$ of Lee medium were inoculated with a loopful of blastoconidia from a $18-24 \mathrm{~h}$ slant culture and placed in a gyratory incubator ( 200 r.p.m.) at $28^{\circ} \mathrm{C}$ for $12-14 \mathrm{~h}$ until the $\mathrm{OD}_{600}$ equalled 0.6 (early-exponential growth phase) as measured with a Perkin-Elmer Coleman 250 spectrophotometer. Blastoconidia were collected from the culture medium by centrifugation at $3000 \mathrm{~g}(10 \mathrm{~min})$, and suspended at a concentration of $1 \mathrm{mg}$ dry wt cells $\mathrm{ml}^{-1}$ in sterile glass-distilled water. The suspension was incubated at $28^{\circ} \mathrm{C}$ for $3 \mathrm{~h}$ with shaking and stored at $4{ }^{\circ} \mathrm{C}$ for $72 \mathrm{~h}$ (starvation period). Starved blastoconidia were used to obtain early-exponential-phase cultures by incubating them $\left(200 \mu \mathrm{g}\right.$ dry wt cells $\left.\mathrm{ml}^{-1}\right)$ in fresh Lee medium at $28^{\circ} \mathrm{C}$. For labelling with radioactive precursors, blastoconidia $(0.5 \mathrm{mg}$ dry $\mathrm{wt} \mathrm{ml}^{-1}$ ) were suspended in $50 \mathrm{ml}$ of Lee medium containing $0.37 \mathrm{GBq}$ of $\left[{ }^{14} \mathrm{C}\right]$ protein hydrolysate and incubated at $28^{\circ} \mathrm{C}$ for 30 or $60 \mathrm{~min}$. In order to label the carbohydrate moieties of mannoproteins, blastoconidia were suspended as described above in Lee medium without glucose, supplemented with $1 \%(\mathrm{w} / \mathrm{v})$ casein hydrolysate, $1.2 \%(\mathrm{w} / \mathrm{v})$ galactose and $0.37 \mathrm{GBq}\left[{ }^{14} \mathrm{C}\right]$ mannose as carbon source (Farkas et al., 1974).

Preparation of walls and protoplasts, and isolation of mixed membrane preparations. Blastoconidia were collected from the culture medium by centrifugation at $3000 \mathrm{~g}$ for $10 \mathrm{~min}$, washed twice with chilled distilled water at $0{ }^{\circ} \mathrm{C}$, resuspended in a small volume of $0.001 \mathrm{M}$-PMSF in $0.01 \mathrm{M}$-Tris/ $\mathrm{HCl}$ buffer $(\mathrm{pH} \mathrm{7.2)}$ and broken by shaking for two periods ( $2 \mathrm{~min}$ each) with glass beads $[5 \mathrm{mg}$ beads $(0.45-0.5 \mathrm{~mm}$ in diameter) ( $\mathrm{mg}$ of cells $\left.)^{-1}\right]$ in a vortex mixer. The procedure resulted in complete cell breakage. The cell walls were sedimented $(1200 \mathrm{~g}$ for $10 \mathrm{~min})$ to eliminate membranous and cytoplasmic debris and washed eight times in chilled 0.001 M-PMSF. Isolated walls were stored at $-20^{\circ} \mathrm{C}$ until used. The supernatant fluid following breakage of blastoconidia was centrifuged at $40000 \mathrm{~g}$ for $40 \mathrm{~min}$ to obtain the mixed membrane preparation (P40), and used immediately. Protoplasts were obtained and regenerated as previously described (Elorza et al., 1988). Labelling with glucose was carried out by adding $\left[{ }^{14} \mathrm{C}\right]$ glucose $(8.88 \mathrm{GBq}$ $\left.\mathrm{mmol}^{-1}\right)$. Protoplasts incubated for $4 \mathrm{~h}$ were collected by centrifugation $(1200 \mathrm{~g}, 10 \mathrm{~min})$ and the spent medium was dialysed against distilled water and lyophilized. Sometimes tunicamycin $\left(20 \mu \mathrm{g} \mathrm{ml}^{-1}\right)$ was added to the regeneration medium to prevent $\mathrm{N}$-glycosylation of protein (Chaffin, 1985; Tkacz \& Lampen, 1975).

Solubilization of wall proteins with Zymolyase and preparation of mannan. Walls from $30 \mathrm{mg}$ (dry wt) of blastoconidia were suspended in $0.001 \mathrm{M}-\mathrm{PMSF}$ containing Zymolyase $20 \mathrm{~T}\left(1 \mathrm{mg} \mathrm{ml}^{-1}\right)$ and incubated at $30^{\circ} \mathrm{C}$ for $2 \mathrm{~h}$. The suspension was then centrifuged $(1200 \mathrm{~g}, 15 \mathrm{~min})$, the wall residues discarded and the solubilized material concentrated by lyophilization. The total sugar and protein contents of the samples were determined by the method of Dubois et al. (1956) and by the Lowry method, using mannose and bovine serum albumin as standards, respectively.

For immunoblot analysis the Zymolyase treatment was the same but the walls were previously treated with boiling $2 \%(\mathrm{w} / \mathrm{v})$ SDS to remove non-intrinsic wall materials (Marcilla et al., 1991; Molloy et al., 1989). Mannan (the high-molecular-mass highly polydisperse carbohydrate moiety of the mannoproteins) was isolated as described by Peat et al. (1961).

Partial proteolysis of high-molecular-mass (HMM) mannoproteins. Mannoproteins released by Zymolyase from blastoconidia walls were fractionated in a Sephacryl S-300 column $(100 \times 1.6 \mathrm{~cm})$. The column was equilibrated with $0.01 \mathrm{M}$-phosphate buffer $\mathrm{pH} 7.0$ with $0.05 \mathrm{M}-\mathrm{NaCl}$ and fractions $(1.8 \mathrm{ml})$ collected at a rate of $24 \mathrm{ml} \mathrm{h}^{-1}$. Aliquots $(50 \mu \mathrm{g}$ of protein) of the material eluted in the void volume were digested with staphylococcal V8 protease $(15 \mu \mathrm{g})$ in $0.1 \mathrm{M}-\mathrm{Tris} / \mathrm{HCl} \mathrm{pH} 7.4$ in a final volume of $70 \mu \mathrm{l}$ (Cleveland, 1983). The reaction mixtures were incubated at $37^{\circ} \mathrm{C}$ and after $30 \mathrm{~min}$ and $180 \mathrm{~min}$ the tubes were heated at $100^{\circ} \mathrm{C}$ for $2 \mathrm{~min}$. Separation of the peptides formed by the limited proteolysis was achieved by SDS-PAGE as described by Laemmli (1970).

Gel electrophoresis and Western blot techniques. Proteins were separated by SDS-PAGE performed basically as described by Laemmli (1970) in $10 \%(\mathrm{w} / \mathrm{v})$ acrylamide gels loaded with $50 \mu \mathrm{g}$ of protein and transferred to nitrocellulose paper (Burnette, 1981).

Proteins in the nitrocellulose papers were immunodetected with polyclonal and monoclonal antibodies as previously described by Casanova et al. (1989). In some experiments the mannoproteins blotted to the nitrocellulose membranes were detected by indirect (Concana- 
valin A-mediated) peroxidase staining (Hawkes, 1982; Millette \& Scott, 1984).

Generation of poly-and monoclonal antibodies. Anti-yeast polyclonal serum $(\mathrm{yPAb})$ was obtained in rabbits after subcutaneous immunization with purified SDS-treated yeast walls (this treatment releases non-covalently bound materials from the isolated cell walls). Blastoconidia cell walls $(50 \mathrm{mg}$ ) previously extracted for $5 \mathrm{~min}$ by boiling with $2 \%(\mathrm{w} / \mathrm{v})$ SDS solution were suspended in $1 \mathrm{ml}$ sterile PBS [0.001 Msodium phosphate $(\mathrm{pH} 7 \cdot 4) / 0 \cdot 15 \mathrm{M}-\mathrm{NaCl}$, emulsified with an equal volume of Freund's incomplete adjuvant, and inoculated subcutaneously into adult female New Zealand White rabbits. Antibodies were purified by ammonium sulphate precipitation and absorbed against yeast mannan obtained chemically (Peat et al., 1961) to remove antimannan antibodies.

A monoclonal antibody (mAb) 1 B12 was generated against the mannoprotein material released by Zymolyase from blastoconidia cell walls. Female BALB/c mice (8-10 weeks old) were immunized with intraperitoneal (i.p.) injections of $100 \mu \mathrm{g}$ antigen emulsified in Freund's complete adjuvant. Two and four weeks later, the mice received a booster i.p. injection with the same amount of antigen emulsified in Freund's incomplete adjuvant. One week after the last injection, the mice were tail-bled and the sera tested for anti-antigen antibody titre by ELISA. After specific immunity was confirmed, a final soluble i.p. injection of $100 \mu \mathrm{g}$ antigen was given to the selected mouse; $3-4 \mathrm{~d}$ later, the animal was killed and its spleen used as the source of $B$ lymphocytes for fusion.

Myeloma cells were cultured in high-glucose Dulbecco's Modified Eagle's Medium (Gibco) supplemented with 2 mm-glutamine, nonessential amino acids, penicillin $\left(100 \mathrm{U} \mathrm{ml}^{-1}\right)$, streptomycin $(100 \mu \mathrm{g}$ $\left.\mu \mathrm{I}^{-1}\right)$, and $15 \%(\mathrm{w} / \mathrm{v})$ foetal bovine serum (s-DMEM). Cell fusion and selection of hybrids were carried out essentially as described by Nowinski et al. (1979). Spleen lymphocytes from the immunized mouse were fused with P3-X63/Ag 8.653 murine myeloma cells (ATCC) at a $5: 1$ ratio using polyethylene glycol 1500 as the fusing agent. The fused cells were distributed in 96-well culture plates (Cell-Cult) at an approximate density of $4 \times 10^{5}$ cells in $100 \mu \mathrm{l}$ of s-DMEM per well; $24 \mathrm{~h}$ after plating, $100 \mu \mathrm{l}$ of HAT selection medium (s-DMEM supplemented with hypoxanthine/aminopterine/thymidine) was added to each well. On day 10 post-fusion, the culture supernatants were screened for the presence of antibodies against the antigen. Positive hybridomas were cloned by limiting dilution on a feeder layer of BALB/c thymocytes (about $10^{6}$ cells per well) and peritoneal macrophages (about 5000 cells per well). Cells were grown in HAT medium for two weeks and then HAT was substituted by HT medium (HAT medium without aminopterine), and the cells were maintained in this medium. Positive clones were expanded and ascites were obtained by injecting hybridoma cells (about $5 \times 10^{6}$ per mouse) into the peritoneal cavity of pristanetreated BALB/c mice. mAbs were purified from clarified ascites by $\left(\mathrm{NH}_{4}\right)_{2} \mathrm{SO}_{4}$ precipitation followed by ion-exchange chromatography on DEAE-Sepharose. $\mathrm{mAb}$ classes and subclasses were determined by ELISA using a Bio-Rad isotyping kit according to the manufacturer's instructions. The titre of both antibodies during the immunization and purification processes was determined by ELISA.

ELISA. Determinations were made basically as described by Voller \& Bidwell (1986) with the following modifications. Wells of NuncImmunoplate I (A/S Nunc) plates were coated with $10 \mu \mathrm{g}$ of polysaccharide material (solubilized by Zymolyase from blastoconidia cells or mannan) in $50 \mu 10.03 \mathrm{M}$-sodium carbonate buffer (pH 9.6) and incubated at $4{ }^{\circ} \mathrm{C}$ for $18 \mathrm{~h}$. The plate was rinsed three times with PBS containing $1 \%(\mathrm{w} / \mathrm{v})$ bovine serum albumin and $0.05 \%$ Tween 20 (PBSBT). Polyclonal antibodies or mAbs purified from ascites fluid was diluted $1: 1000$ with PBSBT, added to the appropriate wells and incubated at $37^{\circ} \mathrm{C}$ for $1 \mathrm{~h}$ in a moist chamber. The wells were then rinsed three times with PBSBT and $50 \mu$ of a $1: 100$ dilution in PBSBT of goat anti-mouse (for mAbs) or anti-rabbit (for polyclonal antibodies) polyvalent immunoglobulins conjugated with peroxidase were added to each well. After incubation for $1 \mathrm{~h}$ at $37^{\circ} \mathrm{C}$, the wells were rinsed with $o$-phenylenediamine, the plate was incubated in the dark for $10 \mathrm{~min}$, and the reaction was stopped by the addition of $25 \mu \mathrm{l} 3 \mathrm{M}-\mathrm{H}_{2} \mathrm{SO}_{4}$ to each well. The colour intensity was determined at $492 \mathrm{~nm}$ with an automated plate reader (Titertek Multiskan Plus).

Chemicals. Zymolyase 20T was from Miles Laboratories. PMSF, tunicamycin, Concanavalin A, peroxidase and the other usual chemicals were from Sigma. Polyethylene glycol 1500 and staphylococcal V8 protease were from Boehringer Mannheim. Radioactive compounds were from Amersham.

\section{Results}

Analytical gel filtration of the mannoproteins released from the yeast cell walls by Zymolyase and the mannoproteins secreted by protoplasts

To determine specific changes in the mannoproteins during their incorporation into the cell wall, the filtration profiles from a Sephacryl S-300 gel column of the material secreted by regenerating protoplasts and the material solubilized by Zymolyase treatment of isolated cell walls were compared. Both protoplasts and yeast cells were labelled with $\left[{ }^{14} \mathrm{C}\right]$ glucose. With the Zymolyase material, a main narrow peak of radioactivity was eluted in the exclusion volume $\left(V_{\mathrm{e}} / V_{0} 1 \cdot 00-1 \cdot 30\right)$. The leading part of this peak also showed a shoulder formed by material retained by the gel (Fig. 1). When the material secreted into the medium by regenerating protoplasts was analysed, the radioactivity was distributed throughout the column (Fig. 1), but the first material eluted, i.e. the molecules with higher molecular masses, was included in the gel $\left(V_{\mathrm{e}} / V_{0}>1 \cdot 3\right)$, indicating that the mannoproteins secreted by protoplasts have smaller

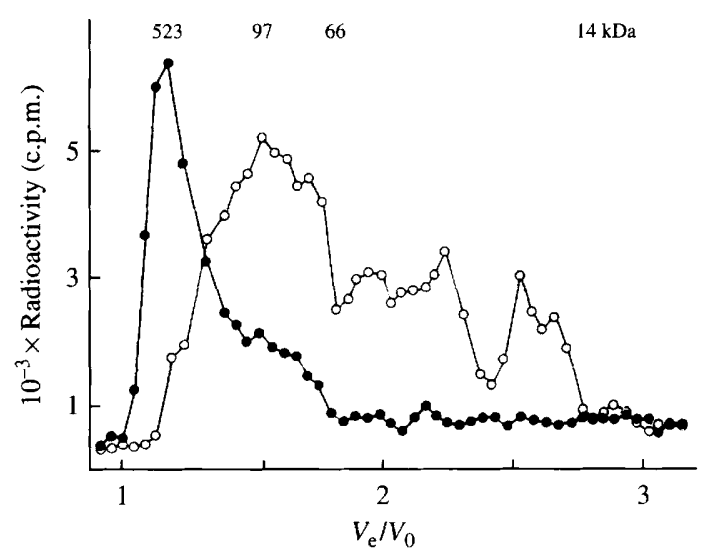

Fig. 1. Analytical gel filtration on a Sephacryl S-300 column $(100 \times 1.6 \mathrm{~cm})$ of the material labelled with $\left[{ }^{14} \mathrm{C}\right] \mathrm{glucose}$ released by Zymolyase from the blastoconidia cell walls of $C$. albicans $(0)$ or secreted by protoplasts $(O)$. The elution positions of BSA $(66 \mathrm{kDa})$ and lysozyme (14 kDa) and the elution range of glycosylated invertase measured enzymically (523-97 kDa) are shown. 
Table 1. Effect of tunicamycin on the incorporation of protein and mannose into yeast cells of $C$. albicans

A cell culture was divided into four aliquots, two of which were supplemented with tunicamycin $\left(20 \mu \mathrm{g} \mathrm{ml}^{-1}\right)$ while the others were used as control cultures. One of each type of culture (treated and untreated) was supplemented with $\left[{ }^{14} \mathrm{C}\right]$ protein hydrolysate or $\left[{ }^{14} \mathrm{C}\right]$ mannose in the presence of galactose (see Methods) and incubated at $28^{\circ} \mathrm{C}$. After 30 and $60 \mathrm{~min}$, samples were taken and the radioactivity determined. The values given are the mean of three experiments and are expressed as the ratio [c.p.m. in tunicamycin treated cell culture]/[c.p.m. in control culture $(20000)]$. The SD values were never higher than $\pm 10 \%$ of the mean.

\begin{tabular}{|c|c|c|c|c|}
\hline & \multicolumn{4}{|c|}{ Cells labelled with: } \\
\hline & \multicolumn{2}{|c|}{$\begin{array}{l}{\left[{ }^{14} \mathrm{C}\right] \text { Protein }} \\
\text { hydrolysate }\end{array}$} & \multicolumn{2}{|c|}{$\left[{ }^{14} \mathrm{C}\right]$ Mannose } \\
\hline & $30 \mathrm{~min}$ & $60 \mathrm{~min}$ & $30 \mathrm{~min}$ & $60 \mathrm{~min}$ \\
\hline Total cells & 0.83 & 0.82 & $0 \cdot 48$ & $0 \cdot 49$ \\
\hline Total walls & 0.68 & 0.55 & 0.22 & 0.22 \\
\hline $\begin{array}{l}\text { Material solubilized } \\
\text { from walls by } \\
\text { Zymolyase }\end{array}$ & 0.59 & 0.62 & $0 \cdot 16$ & $0 \cdot 16$ \\
\hline
\end{tabular}

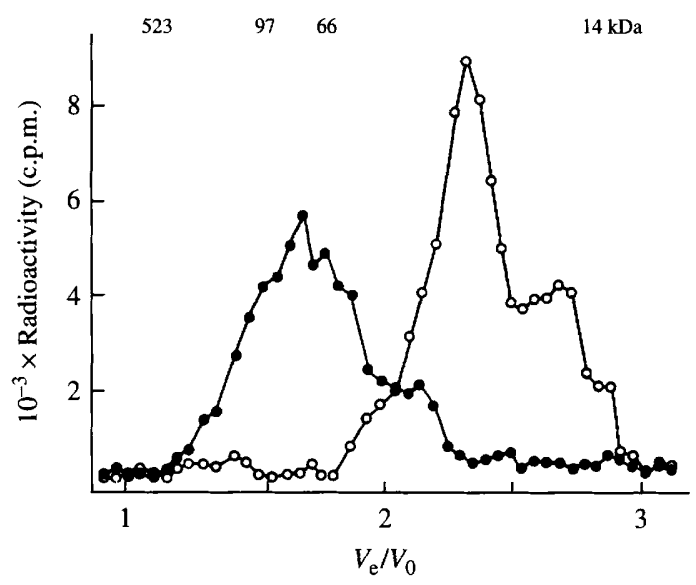

Fig. 2. Analytical gel filtration on a Sephacryl S-300 column of the materials obtained from the blastoconidia cell wall of $C$. albicans and protoplasts after incubation with $\left[{ }^{14} \mathrm{C}\right]$ glucose in the presence of tunicamycin. Material released by Zymolyase from the cell walls; $\bigcirc$, material secreted by protoplasts. The molecular mass markers were the same as in Fig. 1.

molecular masses than the materials released from the walls by Zymolyase.

\section{Analytical gel filtration of the wall proteins obtained from cells and protoplasts incubated in the presence of tunicamycin}

To investigate whether the difference in molecular mass between the mannoproteins secreted by protoplasts and those liberated from the walls by Zymolyase was due to the protein or to the glycosidic part of the molecules, blastoconidia were incubated with tunicamycin in the presence of either $\left[{ }^{14} \mathrm{C}\right]$ mannose plus galactose $(1 \cdot 2 \%$, $\mathrm{w} / \mathrm{v})$ to reduce the interconversion of mannose to glucose (Farkas et al., 1974), or $\left[{ }^{14} \mathrm{C}\right]$ protein hydrolysate (Table 1). After 30 min incubation, total protein synthesis was slightly lowered by tunicamycin, but incorporation of mannose was reduced by approximately $50 \%$. Incorporation of amino acids into the walls was still high after $30 \mathrm{~min}(68 \%$ of the control) whereas mannose incorporation was only $22 \%$ of the control. Furthermore, the $\left[{ }^{14} \mathrm{C}\right]$ mannose-labelled carbohydrate in the mannoproteins solubilized by Zymolyase from tunicamycintreated cells was significantly reduced whereas protein labelling was much less affected $(16 \%$ and $62 \%$ of control values, respectively). Similar results have been obtained previously with protoplasts (Elorza et al., 1988), and nucleic acid and protein accumulation is unchanged for some time following addition of tunicamycin to actively growing blastoconidia cells (Chaffin, 1985).

Radiolabelled material released by Zymolyase from the cell walls or secreted by protoplasts incubated in the presence of $\left[{ }^{14} \mathrm{C}\right]$ glucose and tunicamycin was analysed using Sephacryl S-300 column chromatography (Fig. 2). The material released by Zymolyase from whole walls was eluted with a very broad profile $\left(V_{\mathrm{e}} / V_{0} 1 \cdot 4-2 \cdot 0\right)$ and was significantly retarded by the gel in relation to the material obtained in the absence of tunicamycin $\left(V_{\mathrm{e}} / V_{0}\right.$ $1 \cdot 00-1 \cdot 30$, Fig. 1), hinting that a significant part of the molecular mass of the molecules solubilized by Zymolyase was due to their carbohydrate moieties. Furthermore, the material secreted by the tunicamycintreated protoplasts was also retained by the gel $\left(V_{\mathrm{e}} / V_{0}\right.$ $2-2 \cdot 5$, Fig. 2) to a greater extent than the material from untreated protoplasts (compare Figs 1 and 2), supporting the view that a significant part of the molecular mass of the protein-containing material of the wall was due to $\mathrm{N}$ linked sugar whose formation was sensitive to tunicamycin.

\section{Immunological detection of cell wall proteins and their probable precursors}

It was of interest to examine the relationship between the mannoproteins secreted by protoplasts and those incorporated into the cell wall to determine if any of the former were possible precursors of the latter. Polyclonal and monoclonal antibodies were used to study the proteins present in the mixed membrane preparation (P40), protoplast supernatants and wall digests.

Purified yeast cell walls, extracted with SDS, were used to immunize rabbits, and the specificity of the polyclonal antiserum (yPAb) generated was analysed by ELISA. As 
Table 2. ELISA of blastoconidia cell wall antigen with $y P A b$ and $m A b 1 B 12$

Total Zymolyase-released material from isolated blastoconidia cell walls and mannan obtained from blastoconidia walls $(10 \mu \mathrm{g}$ sugar per well) was used in the coating (solid phase) of the wells. In the case of mannan, the titres were also determined by the sandwich technique (results in parentheses): the wells were coated initially with the antibody, then mannan was added and finally the antibody again. The values are the mean of three separate experiments and the SD values were never higher than $\pm 10 \%$ of the mean.

\begin{tabular}{lcc}
\hline \hline & \multicolumn{2}{c}{$A_{492}$} \\
\cline { 2 - 3 } Antibody & $\begin{array}{c}\text { Zymolyase-released } \\
\text { material }\end{array}$ & Mannan \\
\hline Preimmune serum & $0 \cdot 10$ & $0 \cdot 13(0 \cdot 10)$ \\
yPAb & 0.83 & $0 \cdot 30(0 \cdot 29)$ \\
1B12 & $1 \cdot 20$ & $0 \cdot 18(0 \cdot 10)$ \\
\hline \hline
\end{tabular}

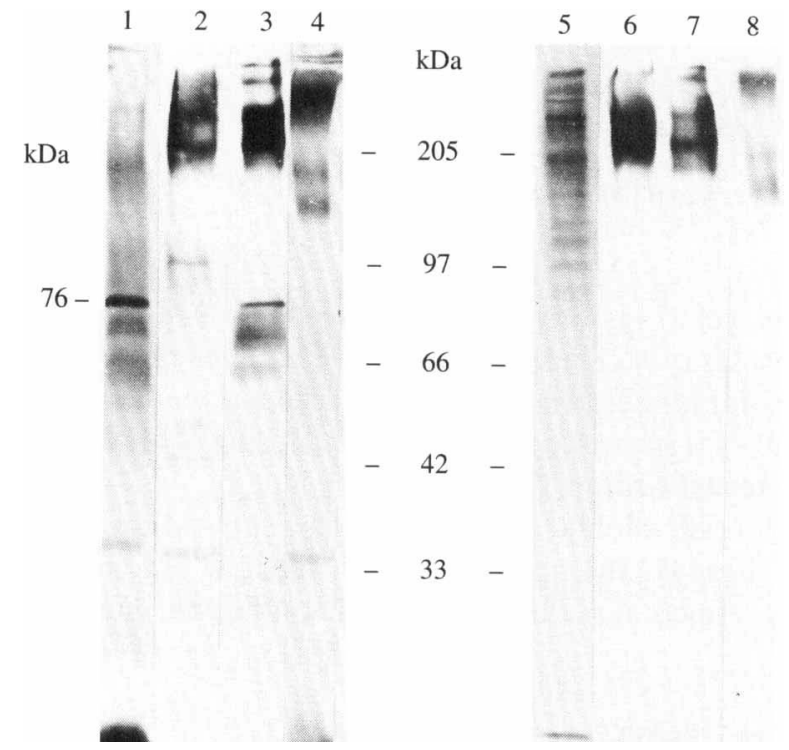

Fig. 3. Western blots stained with anti-yeast polyclonal (lanes 1-4) and monoclonal (lanes 5-8) antibodies. Lanes: 1 and 5, mixed membrane preparation; 2 and 6 , protoplast supernatants obtained by incubation without tunicamycin; 3 and 7 , protoplast supernatants obtained by incubation with tunicamycin; 4 and 8 , Zymolyase-released wall material.

shown in Table 2, the yPAb preparation recognized epitopes from materials released from blastoconidia, probably involving both carbohydrate (mannan gave a positive result) and protein (for the antigens detected by Western blotting, see below). On the other hand, the IgM $\mathrm{mAb}(1 \mathrm{~B} 12)$ reacted with the materials released from blastoconidia cell walls by Zymolyase, but did not react with chemically purified mannan (Table 2 ), suggesting that this $\mathrm{mAb}$ reacts with a protein or a small $O$-linked oligosaccharide epitope. After $\beta$-elimination of the Zymolyase-released materials (Elorza et al., 1988) reactivity with $\mathrm{mAb} 1 \mathrm{~B} 12$ was retained (data not shown), suggesting that the epitope is not related to an $O$ glycosylated epitope. The yPAb reacted with a major $76 \mathrm{kDa}$ antigen in the membrane preparation with several ill-defined bands with apparent molecular masses ranging from below $40 \mathrm{kDa}$ to over $200 \mathrm{kDa}$ (Fig. 3, lane 1).

In the material secreted by protoplasts yPAb revealed mainly high-molecular-mass (HMM) polydisperse material (greater than $205 \mathrm{kDa}$ ) and some minor bands with higher mobility (Fig. 3, lane 2). After protoplasts had been incubated in the presence of tunicamycin, the HMM material was still observed, with five to six new bands with molecular masses between 60 and $80 \mathrm{kDa}$ (Fig. 3, lane 3). When the material released from the walls by Zymolyase was analysed with yPAb (Fig. 3, lane 4), four HMM bands were the only material recognized.

To examine the possible precursor-product relationship between the $N$-glycosylated proteins secreted by regenerating protoplasts and the HMM mannoproteins released from blastoconidia walls by Zymolyase, the following experiment was carried out. Specific polyclonal antibodies against the protoplast bands with molecular masses between 60 and $80 \mathrm{kDa}$ (Fig. 3, lane 3) were obtained from the yPAb by affinity purification by the method described by Olmsted (1981) using nitrocellulose strips of the blotted antigens. These antibodies reacted with HMM mannoprotein bands released by the glucanase complex from blastoconidia walls (data not shown).

To follow the process of incorporation of a specific antigen into the walls, we used mAb 1 B12 (Fig. 3, lanes 5-8). The mAb reacted with several bands in the mixed membrane preparation ( $\mathrm{P} 40)$, one having an apparent molecular mass of about $80 \mathrm{kDa}$, and two slowermigrating bands ( $>205 \mathrm{kDa}$ ) which were the most abundant (Fig. 3, lane 3). Two polydisperse bands were detected by the $\mathrm{mAb}$ in supernatants of protoplasts incubated in either the absence or presence of tunicamycin (Fig. 3, lanes 6 and 7). With material obtained by degradation of the purified walls with Zymolyase (Fig. 3, lane 8), four bands, probably identical with those detected by the yPAb (Fig. 3, lane 4), were revealed.

To prove that the complexes released from the cell walls carried the immunogen detected by $\mathrm{mAb} 1 \mathrm{~B} 12$, the mannoprotein material obtained from the cell walls and eluted in the void volume from the Sephacryl column (Fig. 1) was subjected to limited proteolysis with staphylococcal V8 protease (see Methods). Western blots stained with mAb $1 \mathrm{~B} 12$ showed several bands with molecular masses down to $70-80 \mathrm{kDa}$ (Fig. 4). No smaller immunoreactive fragment accumulated with 


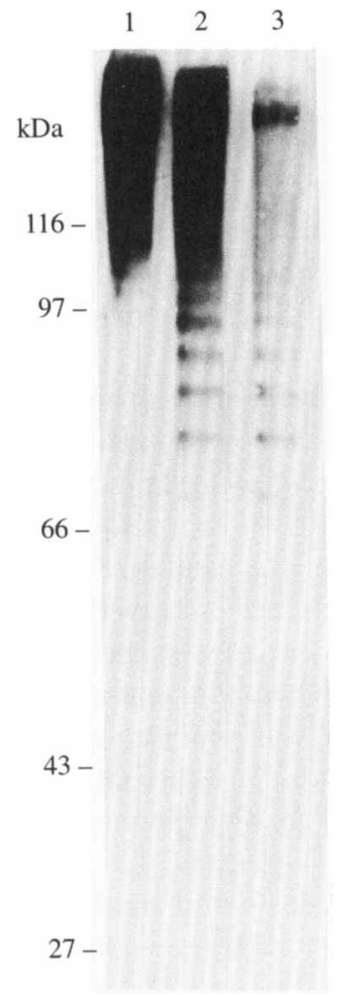

Fig. 4. Western blot stained with $\mathrm{mAb} 1 \mathrm{~B} 12$ of a partial proteolytic digest of the cell wall. Material eluted in the void volume of a Sephacryl column (Fig. 1) was treated with V8 protease, fractionated by electrophoresis and, after blotting, was detected with mAb $1 \mathrm{~B} 12$. Lanes: 1: undigested material; 2, material digested for $30 \mathrm{~min} ; 3$, material digested for $180 \mathrm{~min}$.

time, probably because of degradation of the epitope recognized by $\mathrm{mAb} 1 \mathrm{~B} 12$. This was deduced from the different reactivity of the $\mathrm{mAb}$ in each sample.

Concanavalin A-peroxidase staining of material secreted by protoplasts and released from walls by Zymolyase

The presence of mannose residues in the proteins secreted by the protoplasts was shown by Concanavalin Aperoxidase staining (Fig. 5). This is an extremely sensitive method that detects mannoproteins after blotting from polyacrylamide gels to nitrocellulose paper (Hawkes, 1982). Protoplasts secreted large amounts of highly polydisperse materials of mannoproteins ranging in molecular mass from about $20 \mathrm{kDa}$ to higher than was resolvable in the separating gel (Fig. 5, lane 1). The HMM material was absent when protoplasts were incubated with tunicamycin. New bands representing proteins with molecular masses of $45-70 \mathrm{kDa}$ were secreted by protoplasts in the presence of tunicamycin, with a dominant one of about $60 \mathrm{kDa}$ together with two bands of low mobility that remained in the upper part of

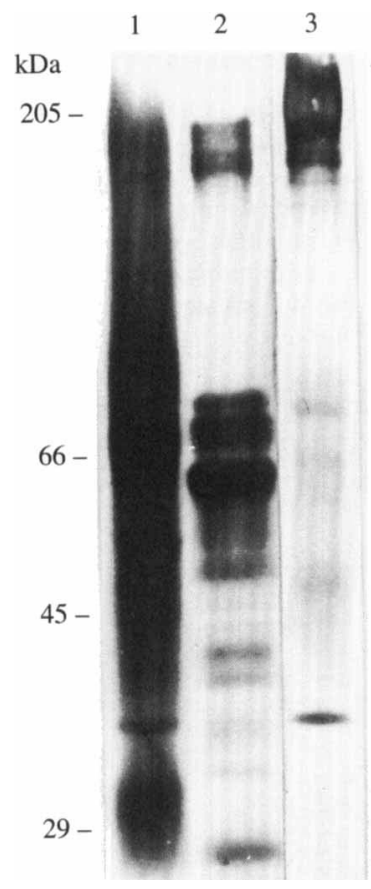

Fig. 5. Concanavalin A-peroxidase staining of Western blots of protoplast supernatants obtained by incubation in the absence (lane 1) or in the presence of tunicamycin (lane 2), and of Zymolyase-released wall material (lane 3).

the gel (Fig. 5, lane 2). These bands with molecular masses of 45-70 kDa seemed the same as those detected by immunoblotting with yPAb, whereas the slow-moving bands appeared to be equivalent to the HMM material detected with mAb 1B12 (Fig. 3, lane 7). Analysis of the material solubilized by Zymolyase showed the presence of four HMM mannoproteins, and low amounts of an ill-defined material in the middle molecular mass range.

\section{Discussion}

Wall extension in $C$. albicans requires the addition of new molecules of glucan(s), chitin and mannoproteins to the wall structure. For mannoproteins, the new molecules are probably synthesized in the rough endoplasmic reticulum as for Saccharomyces cerevisiae (Schekman \& Novick, 1982) and, following their glycosylation, are secreted into the periplasmic space. There they should interact with other molecules, resulting in the formation of covalent or ionic bonds within the cell wall itself (Calderone \& Braun, 1991; Sentandreu et al., 1991). Wall mannoproteins must be among the materials present in membrane preparations involved in secretion and in the supernatant fluids of regenerating protoplasts. The HMM materials secreted by protoplasts had molecular masses smaller than the materials released from the isolated walls following degradation of the 
glucan skeleton by Zymolyase (Fig. 1). Therefore it is possible that the materials released by Zymolyase contained more than one of the mannoprotein molecules secreted and detected in the protoplast supernatant. An important conclusion that can be drawn from these results is that a substantial part of the wall protein may be connected to the glucan skeleton, because it was solubilized by the $\beta$-glucanase complex. Similar results were found for the material obtained from cells and protoplasts growing in the presence of tunicamycin (Fig. 2). These released proteins are thus smaller and retarded by a molecular filtration column. In the presence of tunicamycin the materials released from the cell walls were larger than those secreted by protoplasts, and this suggests that wall proteins that lack their mannan moieties are still incorporated into the wall, at least for a certain period (Table 1), as has been described in halobacterial cell walls (Wieland et al., 1983). There is however evidence for glucose residues from glucan being covalently attached via a $\beta$-linkage to certain $N$-linked mannan chains of mannoproteins (van Rinsum et al., 1991).

To investigate possible precursors of the wall mannoproteins, we examined the relationships between proteins present in a mixed membrane preparation (P40) and those released into the medium by regenerating protoplasts using immunological techniques able to detect specific cell wall compounds.

The polyclonal antibody preparation raised against SDS-treated cell walls (yPAb) reacted against mannan and, with greater intensity, with the Zymolyasesolubilized material (Table 2), and cross-reacted with the equivalent materials of Sacch. cerevisiae and Yarrowia lipolytica (unpublished results), suggesting that the preparation recognized both carbohydrate and protein epitopes. mAb $1 \mathrm{~B} 12$ detected only epitopes found in the Zymolyase materials of $C$. albicans (Table 2) and tunicamycin-treated $C$. albicans (Fig. 3), and did not cross-react with the Sacch. cerevisiae and Y. lipolytica materials or with the isolated mannan moieties of either organism (unpublished results), suggesting that it is specific to a protein epitope. In the supernatant of protoplasts, yPAb recognized mainly HMM components, some of which were converted to new species with higher electrophoretic mobility following incubation with tunicamycin (Fig. 3, lane 3), implying that they lacked $N$-glycosidic sugar chains. The new bands were probably the same as those detected by Concanavalin A-peroxidase (Fig. 5), which have previously been characterized by fluorography (Murgui et al., 1986). It is therefore possible that the HMM material secreted by regenerating protoplasts is made up of two different families of proteins: one consists of HMM mannoproteins rich in mannan that show a significant reduction in their apparent molecular masses following inhibition of $\mathrm{N}$-glycosylation by tunicamycin; the other family is without the mannan moiety as its mobility does not change when synthesized and secreted in the presence of the drug. Both seem to be $O$-glycosylated because, in the presence of tunicamycin, they are detected with Concanavalin A-peroxidase (Fig. 5). The presence of the latter family of proteins was discovered following immunodetection with $\mathrm{mAb} 1 \mathrm{~B} 12$. In protoplast supernatants HMM materials were detected whose apparent molecular mass did not change following incubation in the presence of tunicamycin (Fig. 3), confirming that they do not possess $N$-linked sugar residues. Bands which migrate similarly have also been detected with other monoclonal antibodies (Sundstrom et al., 1988; Torosantucci et al., 1990).

The epitope that reacted with $\mathrm{mAb} 1 \mathrm{~B} 12$ was present in the membrane preparation with a characteristic ladder-like pattern with an increasing mass of about $15-25 \mathrm{kDa}$, suggesting the possibility that a wall protein is built with several repeated units. This suggestion was validated by the finding that partial digestion of the purified material released by Zymolyase from isolated walls also gave the same ladder pattern (Fig. 4). A similar observation has been described for the surface proteins of Plasmodium falciparum (Kemp et al., 1990) and Trichomonas vaginalis (Alderete \& Neale, 1989; Dailey \& Alderete, 1991), which also contain repetitive antigenic determinants that interfere with the immune response of the host and help the parasite to evade host defences.

The fact that both antibodies reacted with the same HMM mannoprotein bands solubilized by degradation of the glucan network of the walls by Zymolyase (Fig. 3, lanes 4 and 8), and that specific affinity-purified polyclonal antibodies against the bands with molecular masses between 60 and $80 \mathrm{kDa}$ also reacted with them, suggested that both families of mannoproteins are secreted as individual species but are released from the wall as part of supramolecular structures.

We have reported recently that in mycelial cells, a secreted $O$-glycosylated protein shows an increase in molecular mass owing to its association with a $\mathrm{N}$ glycosylated protein (Elorza et al., 1989). The data reported in this paper extend these observations by showing that a similar process also occurs in C. albicans yeast cell walls. These proteins may be connected to the wall by binding to the structural polymers in a way similar to that described in Sacch. cerevisiae, where direct linkages between the protein moieties of mannoproteins and the glucan have been recently reported (van Rinsum et al., 1991).

This work was supported by grants from the Direccion General de Investigación Científica y Técnica (PB90-0424), the Commission of the 
European Communities (EEC Group on Candida albicans Cell Biology and Pathogenicity and $\left.\mathrm{Cl}^{*} .0631 . \mathrm{M}\right)$ and Glaxo, SA. A.M. was supported by a doctoral grant from the Spanish Ministry of Education and Science.

\section{References}

Alderete, J. F. \& Neale, K. A. (1989). Relatedness of structures of a major immunogen in Trichomonas vaginalis isolates. Infection and Immunity 57, 1849-1853.

Anderson, J., Cundiff, L., Schnars, B., Gao, M., Mackenzie, I. \& Soll, D. R. (1989). Hypha formation in the white-opaque transition of Candida albicans. Infection and Immunity 57, 458-467.

Anderson, J., Mihalik, R. \& Soll, D. R. (1990). Ultrastructure and antigenicity of the unique cell wall 'pimple' of the Candida opaque phenotype. Journal of Bacteriology 172, 224-235.

BRAWNeR, D. L. \& CUtLer, J. E. (1986). Ultrastructural and biochemical studies of two dynamically expressed cell surface determinants on Candida albicans. Infection and Immunity 51, 327-336.

BURNETTE, W. N. (1981). Western blotting: electrophoretic transfer of proteins from sodium dodecylsulfate-polyacrylamide gels to unmodified nitrocellulose and radiographic detection with antibody and radioiodinated protein A. Analytical Biochemistry 112, 195-203.

Calderone, R. A. \& Braun, P. C. (1991). Adherence and receptor relationships of Candida albicans. Microbiological Reviews 55, 1-20.

Casanova, M., Gil, M. L., Cardeñoso, L., Martinez, J. P. \& Sentandreu, R. (1989). Identification of wall specific antigens synthesized during germ tube formation by Candida albicans. Infection and Immunity 57, 262-271.

ChafFin, W. L. (1985). Effect of tunicamycin in germ tube and yeast bud formation in Candida albicans. Journal of General Microbiology 131, 1853-1861.

Cleveland, D. W. (1983). Peptide mapping in one dimension by limited proteolysis of sodium dodecyl sulfate-solubilized proteins. Methods in Enzymology 96, 222-229.

Dailey, D. C. \& AldereTe, J. F. (1991). The phenotypically variable surface protein of Trichomonas vaginalis has a single, tandemly repeated immunodominant epitope. Infection and Immunity 59, 2083-2088.

Dubois, M., Gilles, K. A., Hamilton, J. A., Rebers, P. A. \& Smith, F. (1956). Colorimetric method for determination of sugars and related substances. Analytical Chemistry 28, 350-356.

Elorza, M. V., Murgui, A. \& Sentandreu, R. (1985). Dimorphism in Candida albicans: contribution of mannoproteins to the architecture of yeast and mycelial cell walls. Journal of General Microbiology 131, 2209-2216.

Elorza, M. V., Marcilla, A. \& Sentandreu, R. (1988). Wall mannoproteins of the yeast and mycelial cells of Candida albicans: nature of the glycosidic bonds and polydispersity of their mannan moieties. Journal of General Microbiology 134, 2393-2403.

Elorza, M. V., Mormeneo, S., Garcia de la Cruz, S., Gimeno, C. \& SentandReu, R. (1989). Evidence for the formation of covalent bonds between macromolecules in the domain of the wall of Candida albicans. Biochemical and Biophysical Research Communications 162, $1118-1125$.

Farkas, V., Novarit, A., Kasinova, A. \& Bauer, S. (1974). Autoradiographic study of mannan incorporation into growing cell walls of Saccharomyces cerevisiae. Journal of Bacteriology 117, 265-269.

HAWKES, R. (1982). Identification of concanavalin A-binding proteins after sodium dodecyl sulphate-gel electrophoresis and protein blotting. Analytical Biochemistry 123, 143-146.

Kemp, D. J., Couman, A. F. \& Walliker, D. (1990). Genetic diversity in Plasmodium falciparum. Advances in Parasitology 29, 75-128.

Kimura, L. H. \& Pearsall, N. N. (1978). Adherence of Candida albicans to human buccal epithelial cells. Infection and Immunity $\mathbf{2 1}$, 64-68.

LEE, J. C. \& KING, R. D. (1983). Characterization of Candida albicans adherence to human vaginal epithelial cells in vitro. Infection and Immunity 41, 1024-1030.
LAEMmLI, U. K. (1970). Cleaveage of structural proteins during the assembly of the head of bacteriophage T4. Nature, London 227, 680-685.

Lee, K., Buckley, H. R. \& Campbell, C. C. (1975). An aminoacid liquid synthetic medium for the development of mycelial and yeast forms of Candida albicans. Sabouraudia 13, 148-153.

LI, R. K. \& Cutler, J. E. (1991). A cell surface plasma membrane antigen of Candida albicans. Journal of General Microbiology 137, 455-464.

Marcilla, A., Elorza, M. V., Mormeneo, S., Rico, H. \& SentanDREU, R. (1991). Candida albicans mycelial wall structure: supramolecular complexes released by Zymolyase, chitinase and $\beta$ mercaptoethanol. Archives of Microbiology 155, 312-319.

Millette, C. F. \& ScotT, B. K. (1984). Identification of spermatogenic cell plasma membrane glycoproteins by two dimensional electrophoresis and lectin blotting. Journal of Cell Science 65, 233-248.

Molloy, C., Shepherd, M. G. \& Sullivan, P. A. (1989). Identification of envelope proteins of Candida albicans by vectorial iodination. Microbios 57, 73-83.

Murgui, A., Elorza, M. V. \& Sentandreu, R. (1986). Tunicamycin and papulacandin A inhibit incorporation of specific mannoproteins into the walls of Candida albicans regenerating protoplasts. Biochimica et Biophysica Acta 884, 550-558.

Nowinski, R. C., Lostron, M. F., Milton, R. T., Stone, M. R. \& BURNETTE, M. R. (1979). The isolation of hybrid cell lines producing MAb against the p15 (E) protein of ecotropic murine leukemia viruses. Virology 93, 111-126.

Odds, F. C. (editor) (1979). Candida and Candidosis, pp. 29-41. Baltimore: University Park Press.

Olmsted, J. B. (1981). Affinity purification of antibodies from diazotized paper blots of heterogeneous protein samples. Journal of Biological Chemistry 256, 11955-11957.

Peat, S., Whelan, W. J. \& Edwards, T. E. (1961). Polysaccharides of baker's yeast. Part IV. Mannan. Biochemical Journal 1, 29-34.

van Rinsum, J., Klis, F. M. \& Van den Ende, H. (1991). Cell wall glucomannoproteins of Saccharomyces cerevisiae mnn9. Yeast 7 , $717-726$.

SChekman, R. \& Novick, P. (1982). The secretory process and cell surface assembly. In The Molecular Biology of the Yeast Saccharomyces, vol. 2, pp. 361-393. Edited by J. Strathern, E. Jones \& J. Broach. Cold Spring Harbor, NY: Cold Spring Harbor Laboratory.

Sentandreu, R., Martinez, J. P., Elorza, M. V. \& Mormeneo, S. (1991). Relationships between dimorphism, cell wall structure and surface activities in Candida albicans. In Candida albicans: Cellular and Molecular Biology, pp. 72-88. Edited by R. Prasad. Berlin, Heidelberg: Springer-Verlag.

ShePherd, M. G., Poulter, R. T. M. \& Sullivan, P. A. (1985). Candida albicans: biology, genetics and pathogenicity. Annual Review of Microbiology 39, 599-614.

Sobel, J. D., Muller, G. \& Buckley, H. R. (1984). Critical role of germ tube formation in the pathogenesis of candidal vaginitis. Infection and Immunity 44, 576-580.

Soll, D. R., Anderson, J. \& Bergen, M. (1991). The developmental biology of the white-opaque transition in Candida albicans. In Candida albicans: Cellular and Molecular Biology, pp. 20-45. Edited by R. Prasad. Berlin, Heidelberg: Springer-Verlag.

Sonnenberg, A. S. M., Sietsma, J. H. \& Wessels, J. G. H. (1982). Biosynthesis of alkali-insoluble cell wall glucan in Schizophyllum commune protoplasts. Journal of General Microbiology 128, 2667-2674.

Sundstrom, P. M., Tam, M. R., Nichols, E. J. \& Kenny, G. E. (1988). Antigenic differences in the surface mannoproteins of Candida albicans as revealed by monoclonal antibodies. Infection and Immunity 56, 601-606.

Surarit, R., Gopal, P. K. \& ShePherd, M. G. (1988). Evidence for a glycosidic linkage between chitin and glucan in the cell wall of Candida albicans. Journal of General Microbiology 134, 1723-1730.

TKACZ, J.S. \& LAMPEN, J.O. (1975). Tunicamycin inhibition of polyisoprenyl $N$-acetylglucosaminyl pyrophosphate formation in calf-liver microsomes. Biochemical and Biophysical Research Communications 65, 248-257. 
Torosantuci, A., Boccanera, M., Casalinuovo, I., Pellegrini, G. \& CAssone, A. (1990). Differences in the antigenic expression of immunomodulatory mannoprotein constituents on yeast and mycelial forms of Candida albicans. Journal of General Microbiology 136, 1421-1428.

Voller, A. \& BidWell, D. (1986). Enzyme-linked immunoadsorbent assay. In Manual of Clinical Laboratory Immunology, pp. 99-109. Edited by M. R. Rose, H. Friedman \& J. L. Faehey. Washington, DC: American Society for Microbiology.

Wessels, J. G. H., Sietsma, J. H. \& SonNenberg, A. S. M. (1983). Wall synthesis and assembly during hyphal morphogenesis in Schizophylum commune. Journal of General Microbiology 129, 1607-1616.

Wessels, J. G. H., Mol, P. C., Sietsma, J. H. \& Vermeulen, C. A. (1990). Wall structure, wall growth, and fungal cell morphogenesis. In Biochemistry of Cell Walls and Membranes in Fungi, pp. 81-93. Edited by P. J. Kuhm, A. P. J. Trinci, M. J. Jung, M. W. Goosey \& L. G. Copping. Berlin, Heidelberg: Springer-Verlag.

Wieland, F., Heitzer, R. \& Shaefer, W. (1983). Asparaginylglucose: novel type of carbohydrate linkage. Proceedings of the National Academy of Sciences of the United States of America 80, 5470-5474. 